\title{
Hematologia e tempo de migração de mácrofagos em surubim Pseudoplatystoma spp. frente a inoculação de Saccharomyces cerevisae
}

\author{
Hematology and time of macrophage migration catfish \\ Pseudoplatystoma spp. front of inoculation Saccharomyces cerevisiae
}

\author{
André Luiz Nunes ${ }^{1 *}$; Robson Andrade Rodrigues ${ }^{1}$; Leticia Emiliani Fantini ${ }^{1}$; \\ Nandara Soares de Oliveira ${ }^{2}$; Pamela Thainara do Nascimento Veiga ${ }^{2}$; \\ Rodrigo Yutaka Dichoff Kasai ${ }^{3}$; Cristiane Meldau de Campos $^{4}$
}

\begin{abstract}
Resumo
Neste trabalho foi estudada a definição do tempo de atividade fagocítica dos macrófagos na cavidade celomática de surubim Pseudoplatystoma spp. e as alterações hematológicas e bioquímica após a inoculação de Saccharomyces cerevisae. Foram utilizados 24 peixes, com peso de 15,6 \pm 4,3 g. O delineamento utilizado foi inteiramente casualizado, e os tempos de incubação foram de uma, duas e três horas, e um grupo controle, sendo utilizados seis peixes por grupo. Na inoculação foi injetado intracelomaticamente 1,5 mL de solução de levedura Saccharomyces cerevisiae na concentração de 9.000 células $\mathrm{mm}^{-3}$. As variáveis hematológicas e bioquímicas analisadas foram: hematócrito, hemoglobina, número total de eritrócitos, volume corpuscular médio, concentração de hemoglobina corpuscular média, contagens total de trombócitos e diferencial de leucócitos e glicose. Foram avaliados a capacidade e índice fagocítico de macrófagos. Foi realizada análise de variância $(\mathrm{P}<0,05)$ e as médias com diferenças significativas, foram comparadas pelo teste de Tukey a 5\%. A concentração de eosinófilos foi menor nos tempos de duas e três horas quando comparados ao grupo controle. Não houve diferença significativa para a glicose plasmática entre os tempos de incubação. Conclui-se que o tempo de incubação de duas horas mostrou ser suficiente para promover a migração e ativação máxima dos macrófagos de surubim. Palavras-chave: Aquicultura, fagocitose, hematologia, imunidade, levedura, peixe
\end{abstract}

\begin{abstract}
It was studied in this work the definition of time in phagocytic activity of macrophages in the celomatic cavity in surubim Pseudoplatystoma spp. and the hematological and biochemistry alterations after the inoculation of Saccharomyces cerevisae. 24 fishes weighting an average of 15,6 $\pm 4,3 \mathrm{~g}$ were used. The delineation used was entirely randomized, and the incubation times were one, two and three hours, and a control group, where six fishes were used per group. For inoculation, $1.5 \mathrm{~mL}$ of solution of yeast Saccharomyces cerevisiae in concentration of 9,000 cells mm-3 were injected intraperitoneally. The hematological and biochemistry variables analyzed were: hematocrit, hemoglobin, total number of
\end{abstract}

\footnotetext{
${ }^{1}$ Mestres em Zootecnia, Universidade Estadual de Mato Grosso do Sul, UEMS, Aquidauana, MS. E-mail: andre_lnunes@hotmail. com, leticia.emiliani@hotmail.com; robson.andrade.rodrigues17@hotmail.com

${ }^{2}$ Bolsistas PIBIC da UEMS, curso de Zootecnia, Aquidauana, MS. E-mail: nandaah_soares@hotmail.com; pamela.thaynara@ hotmail.com

${ }^{3}$ Mestre em Biologia Animal, Universidade Federal de Viçosa, UFV, Viçosa, MG. E-mail: rodrigokasai@hotmail.com

${ }^{4}$ Prof $^{a} \operatorname{Dr}^{\mathrm{a}}$ da Universidade Estadual de Mato Grasso do Sul, Aquidauana, MS. E-mail: cmeldau@uems.br

* Autor para correspondência
} 
erythrocytes, mean corpuscular volume, mean corpuscular hemoglobin concentration, trombocyte count of total blood and total count of differential leukocyte and glucose. The phagocytic capacity and index of macrophages were evaluated. Variance analysis was performed $(\mathrm{P}<0.05)$ and the means that showed significative diffence were compared through the Tukey test at $5 \%$. The eosinophills concentration was lower in the times of two and three hours compared to the control group. There was not significative difference to the plasmatic glucose among the times of incubation. The incubation period of two hours proved to be enough to promote migration and optimal activation of serubim macrophages.

Key words: Aquaculture, phagocytosis, hematology, immunity, yeast, fish

\section{Introdução}

O surubim, Pseudoplatystoma spp. produzido no Brasil e comercializado no mercado nacional e internacional é um peixe híbrido resultante do cruzamento entre o Pseudoplatystoma corruscans e Pseudoplatystoma reticulatum (CREPALDI et al., 2006).

O surubim teve sua primeira produção expressiva em 1998, com uma produção de 329 toneladas, e em 11 anos cresceu $546 \%$, atingindo a marca de 2.126,7 toneladas em 2009. Importante ressaltar que o crescimento da produção no período de 2006 a 2009 foi de $94 \%$, mostrando-se bastante consistente e expressivo, com uma média anual de crescimento de $19,4 \%$ (MPA, 2010).

É um dos peixes que possui um alto valor econômico, devido às características da carne e ao rendimento de carcaça, se tornando um produto com grande aceitação nos mercados interno e externo (CREPALDI et al., 2006). Em sistemas de produção intensiva, possui elevados índices de desempenho zootécnico, se tornando competitivo com outras espécies nativas e exóticas. Em razão das qualidades zootécnicas e organolépticas do surubim, houve um rápido crescimento na criação desta espécie, e junto com este crescimento, a probabilidade de ocorrência de doenças e infecções bacterianas também aumentou.

Os peixes sofrem influência de diversos fatores no meio em que são produzidos, dificultando estabelecer padrões do seu estado imunológico, portanto, há um interesse especial em aumentar a resistência às doenças e desenvolver tecnologias que potencializam seu sistema imune nos sistemas intensivos de produção (BALDISSEROTTO, 2002).

O sistema imune é constituído pelo sistema imune inato (não específico) e o adquirido (específico) (ROITT; BROSTOFF; MALE, 1998). O sistema imune inato dos peixes difere de outros vertebrados, por ser mais importante que a resposta adquirida (SAURABH; SAHOO, 2008). Uma defesa celular não específica do sistema imune inato é a fagocitose, e os macrófagos têm um papel importante nesse processo, fazendo a fagocitose do corpo estranho e protegendo o hospedeiro (VERLHAC; GABAUDAN, 1997).

A fagocitose é considerada a resposta celular na qual os fagócitos, por meio de movimentos amebóides, ingerem partículas maiores que $0,5 \mu \mathrm{m}$ utilizando mecanismos que envolvem e degradam microrganismos, partículas poluentes e irritantes (RABINOVITCH, 1995). É realizada por fagócitos, como macrófagos fixos, residentes ou células como macrófagos presentes em todos os compartimentos do corpo e que, portanto, possui um papel importante no estágio inicial de infecções, e também são os primeiros fagócitos a encontrar o microrganismo invasor (DO VALE; AFONSO; SILVA, 2002).

Os macrófagos pertencem ao sistema fagocítico mononuclear e são componentes da imunidade inata, com funções bem estabelecidas na resposta primária à patógenos, assim como na homeostase dos tecidos, coordenação da resposta imune adaptativa, inflamação, resolução e reparo (GEISSMANN et al., 2010). Várias partículas são utilizadas para verificar a atividade dos macrófagos, dentre as principais estão as leveduras e as bactérias, e o monitoramento 
da ingestão é usado para avaliar o efeito desses contaminantes nos macrófagos (BOLS et al., 2001).

Uma das maneiras de avaliar o sistema imunológico é por meio da estimulação da atividade fagocítica pela injeção de leveduras na cavidade celomática dos peixes, onde se pode determinar o tempo de migração de macrófagos, a capacidade fagocítica e o índice fagocítico (SILVA et al., 2002, 2005). A incubação de leveduras pode variar entre as espécies de peixes, e para estimar o índice fagocítico e a capacidade fagocítica é necessário realizar a contagem de leveduras no momento de maior migração de macrófagos e de maior número de leveduras fagocitadas (DIAS et al., 2011).

Os efeitos das práticas de campo nas pisciculturas podem ser avaliados através de alguns parâmetros metabólicos que indicam a severidade de determinado manejo. Desta forma, valores plasmáticos de glicose são ferramentas que auxiliam na avaliação dos manejos realizados com peixes em diferentes locais (INOUE; HACKBARTH; MORAES, 2004).

O presente estudo foi realizado com o objetivo de definir o tempo de maior atividade fagocítica dos macrófagos na cavidade celomática do surubim Pseudoplatystoma spp. por meio da técnica de inoculação da levedura Saccharomyces cerevisiae e verificar possíveis alterações hematológicas e bioquímica após a incubação da levedura.

\section{Material e Métodos}

O experimento foi conduzido no Laboratório de Ictioparasitologia da Universidade Estadual de Mato Grosso do Sul, na Unidade Universitária de Aquidauana, MS. Foram utilizados 24 juvenis do surubim Pseudoplatystoma spp. com peso de 15,6 $\pm 4,3 \mathrm{~g}$ e comprimento de $14,5 \pm 1,5 \mathrm{~cm}$. Adotouse um delineamento inteiramente casualizado, e os tempos de incubação foram de uma, duas e três horas, e um grupo controle, sendo utilizados seis peixes (repetição) por tempo. Os animais foram anestesiados com eugenol a $50 \mathrm{mg} \cdot \mathrm{L}^{-1}$, e em seguida, foi injetado na cavidade celomática $1,5 \mathrm{~mL}$ de solução salina estéril $(0,07 \%)$ com a levedura Saccharomyces cerevisiae na concentração de 9.000 células $\mathrm{mm}^{-3}$. Os peixes do grupo controle não receberam qualquer substância intracelomática e também foram avaliados quanto aos parâmetros hematológicos e bioquímico.

Os peixes foram acondicionados, individualmente, em aquários redondos de dois litros, com aeração para o controle de oxigênio, termostato para controle da temperatura e cronômetros digitais para o controle dos tempos de incubação.

Decorrido o período de incubação, os animais foram anestesiados novamente, e retiradas alíquotas de sangue por punção do vaso caudal, utilizando seringas e agulhas descartáveis e banhadas em EDTA a 3\%. Os parâmetros hematológicos avaliados foram: porcentagem de hematócrito $(\mathrm{Ht})$ pelo método de microhematócrito de Goldenfarb et al. (1971); hemoglobina ( $\mathrm{Hb}$ ) pelo método de cianometahemoglobina de Collier (1944); contagem do número de eritrócitos (Er) em câmara de Neubauer utilizando a diluição de 1:200 em solução de formol-citrato em microscópio óptico (400 X). A partir dos dados de hematócrito, hemoglobina e número de eritrócitos foram calculados o volume corpuscular médio $(\mathrm{VCM})=\mathrm{Ht} \times 10 / \mathrm{Er}$ e a concentração de hemoglobina corpuscular média $(\mathrm{CHCM})=\mathrm{Hb} \times 100 / \mathrm{Ht}$.

Foram confeccionadas extensões sanguíneas em duplicata de cada animal, secas ao ar e coradas pancromicamente com May Grünwald-GiemsaWright (TAVARES-DIAS; MORAES, 2004) para a contagem diferencial de leucócitos, contagem total de trombócitos e leucócitos (HRUBEC; SMITH, 2006). A glicose plasmática foi determinada por meio de Kit Comercial LabTest ${ }^{\circledR}$ e para isso, seringas e agulhas descartáveis utilizadas na colheita sanguínea foram banhadas no antiglícolítico glistab.

Após a colheita de sangue, os animais foram eutanasiados por aprofundamento do plano 
anestésico e feita uma incisão ventral, onde foi realizado o lavado da cavidade peritoneal com 1,5 $\mathrm{mL}$ de solução PBS (Phosphate Buffered Saline $\mathrm{pH} 7,2)$. O líquido contendo as células inflamatórias (macrófagos) foi aspirado com pipeta de Pasteur e em seguida centrifugado a $1500 \mathrm{rpm}$ (251.5 x g) por 5 minutos. Após a centrifugação, o sobrenadante foi desprezado e o restante do precipitado foi depositado entre lâmina e lamínula e observado em microscópia de contraste de fase $(400 \mathrm{X})$ para contagem do número de fagócitos.

A capacidade fagocítica (CF) e o índice fagocítico (IF) de macrófagos nos três diferentes tempos de incubação, foram calculados segundo metodologia de Silva et al. (2002, 2005), em que a Capacidade Fagocítica (CF) é a porcentagem de um determinado tipo celular que está fagocitando, expressa pela equação: $\mathrm{CF}=$ (número de macrófagos fagocitando / total de macrófagos contados) x 100; e o Índice Fagocítico (IF) é o número médio de leveduras no interior das células fagocíticas em que são contadas 100 células, cuja fórmula é: $\mathrm{IF}=\mathrm{n}^{\circ}$ total de leveduras no interior dos fagócitos / $\mathrm{n}^{\mathrm{o}}$ total de fagócitos ativos.

Para a análise estatística dos dados, os resultados dos parâmetros hematológicos, bioquímico, capacidade fagocítica e índice fagocítico, foram submetidos ao Software Estatístico R versão 2.13.0, e realizada a análise de variância (ANOVA) com nível de significância $5 \%$. Quando apresentaram diferenças significativas, as médias foram comparadas pelo teste de Tukey $(\mathrm{P}<0,05)$.

\section{Resultados e Discussão}

Para a série vermelha (hematócrito, hemoglobina e número de eritrócitos), índices hematimétricos e glicose (Tabela 1) foi observado efeito dos diferentes tratamentos $(\mathrm{P}<0,01)$ somente para a concentração de hemoglobina corpuscular média (CHCM), com valores elevados no tempo de duas horas. No entanto, os valores do grupo controle e do tempo de uma hora foram estatisticamente inferiores aos valores obtidos nos tempos de duas e três horas após a inoculação.

Tabela 1. Valores médios ( \pm Erro Padrão) dos parâmetros hematológicos e de glicemia do surubim Pseudoplatystoma spp. nos diferentes tempos de inoculação de leveduras.

\begin{tabular}{lcccccc}
\hline \multirow{2}{*}{ Tempo } & HTC & HB & ER & VCM & CHCM & GLIC \\
\cline { 2 - 7 } & $(\%)$ & $\left(\mathrm{g} \mathrm{dL}^{-1}\right)$ & $\left(10^{6} \mathrm{uL}^{-1}\right)$ & $(\mathrm{fL})$ & $\left(\mathrm{g} \mathrm{dL}^{-1}\right)$ & $\left(\mathrm{g} \mathrm{dL}^{-1}\right)$ \\
\hline Controle & $21,83 \pm 4,07$ & $3,94 \pm 0,92$ & $1,07 \pm 0,19$ & $211,10 \pm 18,12$ & $16,80 \pm 1,60^{\mathrm{b}}$ & $33,05 \pm 7,19$ \\
1h & $23,50 \pm 1,98$ & $4,03 \pm 0,46$ & $1,07 \pm 0,10$ & $224,07 \pm 17,11$ & $17,12 \pm 1,32^{\mathrm{b}}$ & $31,10 \pm 3,29$ \\
2h & $19,67 \pm 3,28$ & $4,91 \pm 0,94$ & $1,11 \pm 0,18$ & $163,28 \pm 19,45$ & $24,50 \pm 1,01^{\mathrm{a}}$ & $28,84 \pm 3,17$ \\
$3 \mathrm{~h}$ & $17,00 \pm 1,37$ & $4,05 \pm 0,55$ & $0,91 \pm 0,07$ & $191,39 \pm 23,89$ & $23,37 \pm 2,17^{\mathrm{a}}$ & $46,00 \pm 4,52$ \\
\hline
\end{tabular}

$\mathrm{HTC}=$ hematócrito; $\mathrm{HB}=$ taxa de hemoglobina; $\mathrm{ER}=$ número de eritrócitos; $\mathrm{VCM}=$ volume corpuscular médio; $\mathrm{CHCM}=$ concentração de hemoglobina corpuscular média; GLIC = glicose. Médias seguidas de letras diferentes na mesma coluna diferem entre si pelo teste de Tukey $(\mathrm{P}<0,05)$.

Fonte: Elaboração dos autores.

Os valores de hemoglobina e o número de eritrócitos do presente estudo não apresentaram diferença estatística entre os tempos, no entanto, as mesmas variáveis estão ligadas à resposta do estímulo estressante do tempo de incubação, pois o estresse causa um aumento da demanda energética. Assim, valores de hemoglobina tendem a serem maiores para tentar suprir o aumento do 
consumo de oxigênio por intermédio do transporte do mesmo na corrente sanguínea (TAVARESDIAS; MORAES, 2004), com isto o CHCM está intimamente ligado aos números de eritrócitos e hemoglobina.

Os eosinófilos, muitas vezes, estão ausentes no sangue periférico dos peixes, e quando estão presentes, aparecem com uma frequência relativamente baixa (TAVARES-DIAS; MORAES, 2004). A maior porcentagem de concentração de eosinófilos (Tabela 2) circulantes no sangue foi no grupo controle, mostrando que nos grupos que receberam a levedura, pois durante o processo inflamatório ou de infecção, eles podem estar migrando para os focos para a realização de processos fagocíticos ou de lesionamento. Os eosinófilos constituem um grupo especial de leucócitos, com capacidade de apreender e lesar patógenos extracelulares maiores, como parasitos que são muito grandes para serem eliminados por fagocitose (KLEIN, 1990).

Tabela 2. Valores médios ( \pm Erro Padrão) dos leucócitos de surubins Pseudoplatystoma spp. nos diferentes tempos de inoculação de leveduras.

\begin{tabular}{lcccc}
\hline Grupos & $\begin{array}{c}\text { MON } \\
\left(\mathrm{uL}^{-1}\right)\end{array}$ & $\begin{array}{c}\text { LIN } \\
\left(\mathrm{uL}^{-1}\right)\end{array}$ & $\begin{array}{c}\text { BAS } \\
\left(\mathrm{uL}^{-1}\right)\end{array}$ & $\begin{array}{c}\text { EOS } \\
\left(\mathrm{uL}^{-1}\right)\end{array}$ \\
\cline { 2 - 5 } Controle & 0 & $9.550,89 \pm 1.361,53$ & $1.360,73 \pm 450,35$ & $2.432,77 \pm 446,85^{\mathrm{a}}$ \\
$1 \mathrm{~h}$ & 0 & $10.510,81 \pm 2.656,50$ & $763,11 \pm 326,59$ & $1.760,60 \pm 573,82^{\mathrm{ab}}$ \\
$2 \mathrm{~h}$ & $15,05 \pm 15,05$ & $6.529,49 \pm 1.952,59$ & $566,07 \pm 117,05$ & $451,75 \pm 175,56^{\mathrm{b}}$ \\
$3 \mathrm{~h}$ & $45,00 \pm 45,00$ & $11.447,14 \pm 3.982,70$ & $338,93 \pm 137,94$ & $596,20 \pm 218,04^{\mathrm{b}}$ \\
\hline \multirow{2}{*}{ Grupos } & $\mathrm{NEU}$ & $\mathrm{CGE}$ & $\mathrm{LI}$ & $\mathrm{LEUC}$ \\
Controle & $(\mathrm{uL})$ & $\left(\mathrm{uL} \mathrm{L}^{-1}\right)$ & $\left(\mathrm{uL}^{-1}\right)$ & $\left(\mathrm{uL}^{-1}\right)$ \\
\cline { 2 - 5 } $1 \mathrm{~h}$ & $18.531,33 \pm 3.123,61$ & $1.078,24 \pm 498,41$ & $266,47 \pm 185,72$ & $33.220,42 \pm 4.626,15$ \\
2h & $14.970,99 \pm 1.827,95$ & $836,60 \pm 236,64$ & $382,07 \pm 189,44$ & $29.224,17 \pm 4.842,66$ \\
$3 \mathrm{~h}$ & $7.661,35 \pm 2.030,31$ & $941,61 \pm 332,05$ & $18,43 \pm 18,42$ & $16.183,75 \pm 3.992,12$ \\
\hline
\end{tabular}

$\mathrm{MON}=$ monócitos; $\mathrm{LIN}=$ linfócitos; $\mathrm{BAS}=$ basófilos; $\mathrm{EOS}=$ eosinófilo; $\mathrm{NEU}=$ neutrófilo; CGE = célula granulocítica especial; $\mathrm{LI}=$ leucócitos imaturos; LEUC = Leucócitos totais; Médias seguidas de letras diferentes na mesma coluna diferem entre si pelo teste de Tukey $(\mathrm{P}<0,05)$.

Fonte: Elaboração dos autores.

Os eosinófilos diferiram significativamente do grupo controle com os tempos de duas e três horas (Tabela 2). Assim, os mesmos podem estar migrando para o foco inflamatório, no caso, a cavidade celomática com levedura, diminuindo a sua concentração na corrente sanguínea. Este grupo de células pode estar ligado tanto a resposta inata, quanto a resposta específica do sistema imune de peixes, no entanto, com os dados apresentados em surubim este grupo celular provavelmente esteja envolvido mais acentuadamente na resposta imune inata. Entretanto os outros parâmetros hematológicos não apresentaram o mesmo comportamento $(\mathrm{P}<0,05)$ (Tabelas 2 e 3$)$. Dias et al. (2011) em estudo com matrinxã Brycon amazonicus encontraram resultados semelhantes após a inoculação de leveduras. 
Tabela 3. Valores médios ( \pm Erro Padrão) de Trombócitos totais de surubins Pseudoplatystoma spp. nos diferentes tempos de inoculação de leveduras.

\begin{tabular}{lc}
\hline Grupos & $\begin{array}{c}\text { TROM } \\
\left(\mathrm{uL}^{-1}\right)\end{array}$ \\
\hline Controle & $8.107,50 \pm 4.096,52$ \\
1h & $9.200,83 \pm 4.944,68$ \\
2h & $1.754,58 \pm 742,60$ \\
3h & $1.923,75 \pm 953,62$ \\
\hline
\end{tabular}

TROM = trombócitos.

Fonte: Elaboração dos autores.

Observou-se diferença $(\mathrm{P}<0,05)$ para a $\mathrm{CF}$ e IF entre o tempo experimental de uma hora quando comparado com duas e três horas. Entretanto, não houve diferença estatística entre os tempos de duas e três horas para essas variáveis (Figuras 1 e 2). O fato dos valores serem menores para CF e IF no tempo de incubação de uma hora, pode estar relacionado com a velocidade de migração dos macrófagos para a cavidade celomática e a sua ativação frente às leveduras.

O tempo experimental de duas horas mostrou ser suficiente para promover a migração e ativação máxima dos macrófagos (Figuras 1 e 2). Dias et al. (2011) verificaram para o peixe nativo matrinxã Brycon amazonicus, que duas horas de incubação foram suficientes para a migração de macrófagos. Existe uma grande variação nos tempos de incubação entre as espécies e vários fatores podem interferir nesse processo, como temperatura, estresse, imunoestimulante utilizado, alimentação, entre outros (DIAS et al., 2011).

Figura 1. Valores médios percentuais da capacidade fagocítica de juvenis de surubim nos diferentes tempos de incubação de leveduras. Médias seguidas de mesma letra não diferem pelo teste de Tukey $(\mathrm{P}<0,01)$.

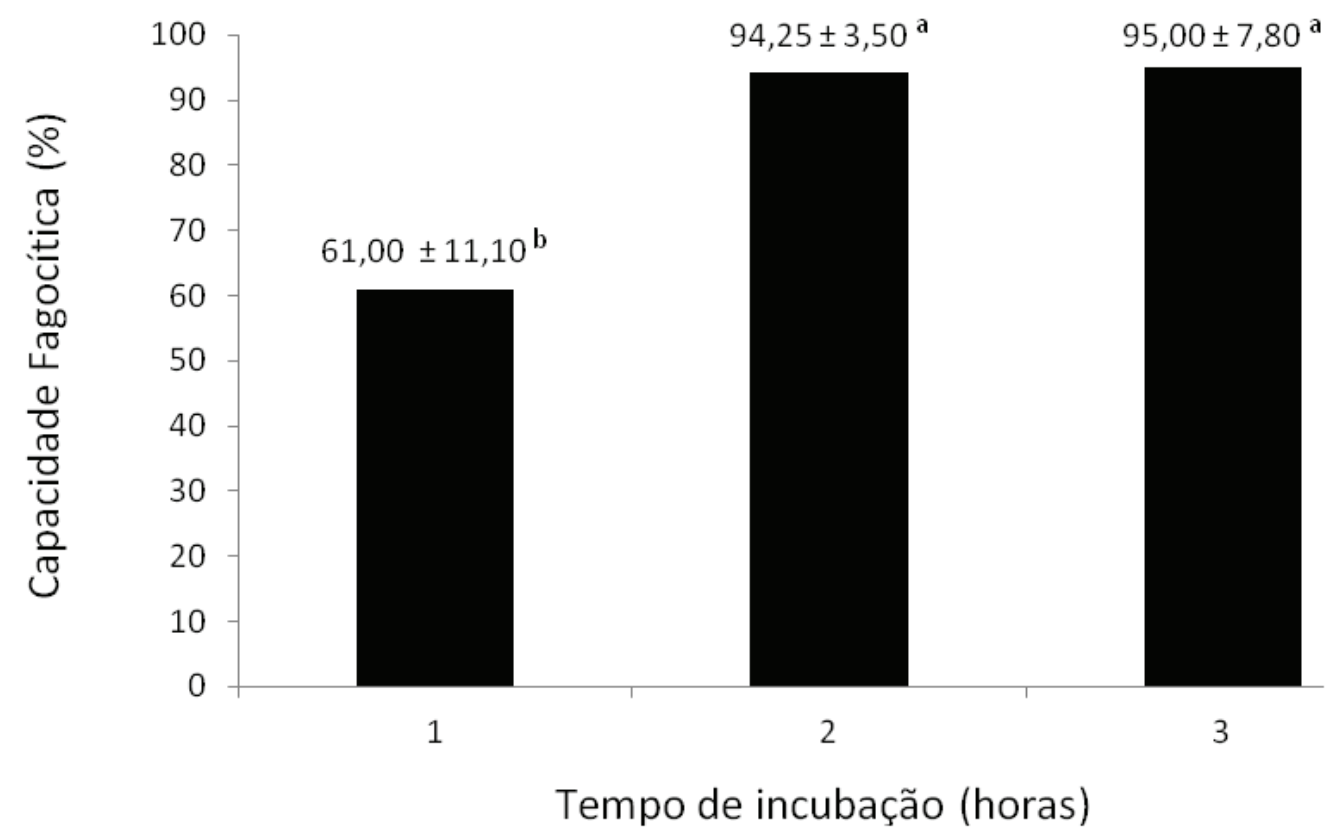

Fonte: Elaboração dos autores. 
Figura 2. Valores médios dos índices fagocíticos de juvenis de surubim nos diferentes tempos de incubação de leveduras. Médias seguidas de mesma letra não diferem pelo teste de Tukey $(\mathrm{P}<0,05)$.

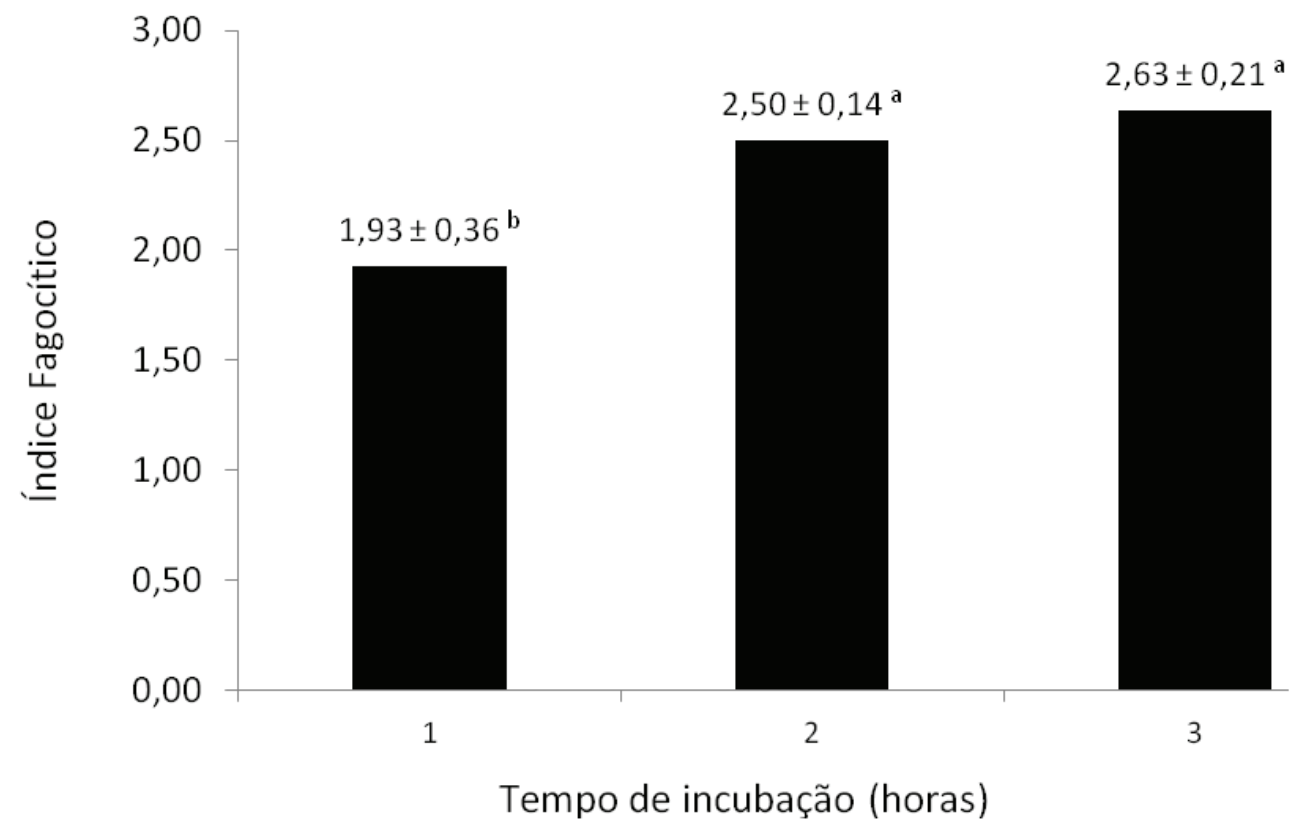

Fonte: Elaboração dos autores.

Os resultados demonstraram que a levedura S. cerevisiae foi capaz de estimular a migração de macrófagos para a cavidade celomática em todos os períodos estudados, sendo um bom imunoestimulante para o estudo da fagocitose. $\mathrm{O}$ resultado foi semelhante ao encontrado por JenschJunior et al. (2006), que avaliaram a levedura na estimulação de macrófagos em Prochilodus scrofa.

\section{Conclusão}

Nas condições deste experimento o tempo de duas horas foi suficiente para promover a migração e ativação máxima dos macrófagos na cavidade celomática de juvenis de surubins Pseudoplatystoma spp. Houve alteração hematológica somente para eosinófilos, sendo menor nos tempos de duas e três horas quando comparados ao grupo controle. Não houve alteração da glicose plasmática dos surubins nos tempos de incubação avaliados.

\section{Agradecimentos}

À Coordenação de Aperfeiçoamento de Pessoal de Nível Superior (CAPES) pela concessão da bolsa de mestrado.

\section{Aspectos éticos}

O presente trabalho foi aprovado pela Comissão de Ética no Uso de Animais da referida Universidade, sob protocolo $n^{\circ}$ 014/2013.

\section{Referências}

BALDISSEROTTO, B. Fisiologia de peixes aplicada à piscicultura. Santa Maria: Editora UFSM, 2002.

BOLS, N. C.; BRUBACHER, J. L.; GANASSIN, R. C.; LEE, L. E. J. Ecotoxicology and innate immunity in fish. Developmental \& Comparative Immunology, Edinburgh, v. 25, n. 8-9, p.853-873, 2001.

COLLIER, H. B. Standardization of blood hemoglobin determinations. Canadian Medical Association Journal, Ottawa, v. 50, n. 6, p. 550-552, 1944. 
CREPALDI, D. V.; FARIA, P. M. C.; TEIXEIRA, E. A.; RIBEIRO, L. P.; COSTA, Â. A. P.; MELO, D. C.; CINTRA, A. P. R.; PRADO, S. A.; COSTA, F. A. A.; DRUMOND, M. L.; LOPES, V. E.; MORAES, V. E. D. O surubin (Pseudoplatystoma $\mathrm{sp}$ ) na aquacultura do Brasil. Revista Brasileira de Reprodução Animal, Belo Horizonte, v. 30, n. 3-4, p. 150-158, 2006.

DIAS, D. C.; TACHIBANA, L.; SERIANI, R.; SANTOS, A. A.; RANZANI-PAIVA, M. J. T.; ROMAGOSA, E. Tempo de migração dos macrófagos em matrinxã, Brycon amazonicus, por meio da técnica de inoculação de leveduras Saccharomyces cerevisiae. Acta Amazônica, Manaus, v. 41, n. 3, p. 421-424, 2011.

DO VAlE, A.; AFONSO, A.; SILVA, M. T. The Professional phagocytes of sea bass (Dicenrtrarchus labrax L.): cytochemical characterisation of neutrophils and macrophages in the normal and inflamed peritoneal cavity. Fish and Shellfish Immunology, Groton, v. 13, n. 3, p. 1-16, 2002.

GEISSMANN, F.; MANZ, M. G.; JUNG, S.; SIEWEKE, M. H.; MERAD, M.; LEY, K. Development of monocytes, macrophages and dendritic cells. Science, Washington, v. 327, n. 5966, p. 656-661, 2010.

GOLDENFARB, P. B.; BOWYER, F. P.; HALL, E.; BROSIUS, E. Reproducibility in the hematology laboratory: the microhematocrit determinations. American Journal of Clinical Pathology, Hagerstown, v. 56, n. 1, p. 35-39, 1971.

HRUBEC, T. C.; SMITH, S. A. Hematology of fish. In: FELDMAN, B. F.; ZINKL, J. G.; JAIN, C. N. Schalm's veterinary hematology. 5. ed. Philadelphia: Lippincott Willians and Wilkins, 2006. p. 1120-1125.

INOUE, L. A. K. A.; HACKBARTH, A.; MORAES, G. Avaliação dos anestésicos 2-phenoxyethanol e benzocaína no manejo do matrinxã Brycon cephalus (Gunther, 1869). Biodiversidade Pampeana, PUCRS, Uruguaiana, v. 2, n. 1, p. 10-15, 2004.
JENSCH-JUNIOR， B. E.; PRESSIONOTTI， L. N.; BORGES, J. C. S.; SILVA, J. R. M. C. Characterization of macrophage phagocytosis of the tropical fish Prochilodus scrofa (Steindachner, 1881). Aquaculture, Amsterdan, v. 251, n. 2-4, p. 509-515, 2006.

KLEIN, J. Defence reactions mediated by phagocytes. In: Immunology. Oxford: Blackwell Scientific

Publications Inc., 1990. p. 311-334.

MINISTÉRIO DA PESCA E AQUICULTURA - MPA. Produção pesqueira e aquícola - estatística 2008-2009.

[S. 1]: Ministério da Pesca e Aquicultura, 2010. 30 p.

RABINOVITCH, M. Professional and non-professional phagocytes: an introduction. Trends in Cell Biology, Cambridge, v. 5, p. 85-88, 1995.

ROITT, I.; BROSTOFF, J.; MALE, D. Immunology. 5. ed. London: Mosby, 1998.

SAURABH, S.; SAHOO, P. K. Lysozyme: an important defence molecule of fish innate immune system. Aquaculture Research, Oxford, v. 39, n. 3, p. 223-239, 2008.

SILVA, J. R. M. C.; PORTO-NETO, L. R.; BORGES, J. C. S.; JENSCH-JUNIOR, B. E. Germicide capacity of macrophages in the Antartic fish Notothenia coriiceps (Richardson, 1844) at $0^{\circ} \mathrm{C}$. Polar Biology, Berlin, v. 28, n. 4, p. 326-328, 2005.

SILVA, J. R. M. C.; STAINES, N. A.; HERNANDEZBLAZQUEZ, F. J.; POTO-NETO, L. R.; BORGES, J. C. S. Phagocytosis and giant cell formation at $0^{\circ} \mathrm{C}$ by macrophage of Notothenia coriiceps. Journal Fish Biology, Scotland, v. 60, p. 466-478, 2002.

TAVARES-DIAS, M.; MORAES, F. R. Hematologia de peixes teleósteos. Ribeirão Preto: M. Tavares-Dias, 2004. $144 \mathrm{p}$.

VERLHAC, V.; GABAUDAN, J. The effect of vitamin $C$ on fish health. Brochure $\mathrm{n}^{\circ} 51002$. Roche Vitamins, 4070 Basle, Switzerland, 1997. 